\title{
Yellow nail syndrome in rheumatoid arthritis: report of three cases
}

\author{
PETER C. MATTINGLY AND DAVID H. BOSSINGHAM \\ From the Rheumatology Unit, Nuffield Orthopaedic Centre, Headington, Oxford OX3 7LD
}

SUMMARY We report the occurrence of the yellow nail syndrome in 3 patients with rheumatoid arthritis. In 2 patients the development of the syndrome was related to severe chest infections, and there was evidence of immunodeficiency, consisting in 1 case of a persistently low serum $\operatorname{IgA}$ level and in the other of a generalised marrow suppression. The third patient gave a history of recurrent sinusitis and showed evidence of previous chest infections and pulmonary fibrosis, but has no gross evidence of immunodeficiency. We have found only 1 previous brief mention of a patient with the yellow nail syndrome and rheumatoid arthritis.

The yellow nail syndrome was first described by Samman and White (1964), who noted the association of persistent oedema and nail discolouration. The nail changes are characteristic and are associated with a very slow growth rate. The nails are excessively curved from side to side, and their colour is usually pale yellow but may be slightly green. Onycholysis may occur, and partially separated nails sometimes show a distinct hump. Occasionally the nails will show cross ridging owing to variations in the rate of growth. Ten of the 13 patients reported by Samman and White (1964) also had oedema, and lymphangiography showed abnormalities in the 4 patients on whom it was performed. They concluded that defective lymphatic drainage was an important aetiological factor.

Emerson (1966) described 3 patients with chronic and otherwise unexplained pleural effusions and attributed the condition to a deficiency of the lymphatics draining the pleural space. All 3 patients had chronic lymphoedema of the legs, hands, and face, and 2 of them had abnormal yellow nails. Hiller et al. (1972) reported 12 patients with various combinations of yellow nails, lymphoedema, pulmonary complications (mainly recurrent pleural effusions and bronchiectasis), and sinusitis. We have found only 1 brief mention in the literature of a patient with the yellow nail syndrome who also had rheumatoid arthritis (Sharvill, 1966).

Accepted for publication 13 December 1978. Correspondence to Dr Mattingly.

\section{Case reports}

CASE 1

A woman aged 30 developed rheumatoid arthritis in 1967. She was treated with gold injections with some improvement but then developed a rash which necessitated stopping the gold, and in October 1974 D-penicillamine was started. In December 1975 she was admitted to another hospital with a productive cough, dyspnoea, and pleuritic chest pain. Investigations at that time showed growth of Streptococcus pneumoniae from blood cultures. Chest $x$-ray showed bilateral pleural effusions. Pleural fluid was straw coloured, with a protein level of $35 \mathrm{~g} / 1$, and cytology showed polymorphs, lymphocytes, red blood cells, scattered mesothelial cells, and macrophages, but no malignant or 'rheumatoid' cells (Boddington et al., 1971). She was treated with antibiotics and gradually improved, although she continued to have a productive cough for several months. Shortly after the acute episode of pneumonia she noticed that her finger and toe nails had turned yellow and that her ankles tended to swell after prolonged standing.

She was admitted to the Nuffield Orthopaedic Centre in August 1976 after a flare-up of her widespread, nodular, erosive, seropositive rheumatoid arthritis. Examination showed very slow-growing yellow finger and toe nails, which were thickened and had increased curvature. 
Investigations showed $\mathrm{Hb} 13 \cdot 3 \mathrm{~g} / \mathrm{dl}$; ESR 83 $\mathrm{mm} / 1$ st hour; white blood cells $4.4 \times 10^{9} / 1$; platelets $149 \times 10^{9} / 1$; urea $4.3 \mathrm{mmol} / 1$; total protein $84 \mathrm{~g} / \mathrm{l}$; albumin $39 \mathrm{~g} / \mathrm{l}$; liver function tests normal; creatinine clearance $89 \mathrm{ml} / \mathrm{min}$; serum IgG $27.4 \mathrm{~g} / 1$ (normal 7.2-19.0), serum IgA $0.39 \mathrm{~g} / 1$ (normal $0 \cdot 8-5 \cdot 0$ ), serum IgM $3.6 \mathrm{~g} / 1$ (normal $0 \cdot 5-2 \cdot 0$ ); latex test positive and differential agglutination test (DAT) titre 1:64; antinuclear antibodies (ANA) positive at a titre of $1: 160$. Chest $x$-ray showed small bilateral pleural effusions and respiratory function tests a slight reduction from the predicted values.

The dose of D-penicillamine was increased from $750 \mathrm{mg} /$ day to $1 \mathrm{~g} /$ day, but despite this her arthritis remained uncontrolled, and in September 1976 she was started on prednisolone $5 \mathrm{mg} / \mathrm{day}$. By June 1977 she had developed persistent bilateral pitting oedema of the legs. In January 1978 the nails remained deformed and yellow, and the leg oedema persisted despite intermittent diuretic therapy. Repeat investigations showed: white cell count $9.4 \times 10^{9} / 1$; ESR $98 \mathrm{~mm} / 1$ st hour; ANA positive at a titre of $1: 640$; serum IgG $28.0 \mathrm{~g} / \mathrm{l}$, serum IgA $0 \cdot 2 \mathrm{~g} / \mathrm{l}$, and serum $\operatorname{IgM} 4.4 \mathrm{~g} / \mathrm{l}$.

In March 1978 D-penicillamine was stopped in view of the falling IgA level, persistent slight haematuria and proteinuria, and lack of clinical response to the drug. In May 1978 her IgA level was still very low at $0.02 \mathrm{~g} / \mathrm{l}$, and in July 1978 it was $0 \cdot 1 \mathrm{~g} / \mathrm{l}$, while the IgG and IgM levels remained raised at $30.0 \mathrm{~g} / 1$ and $6 \cdot 1 \mathrm{~g} / 1$ respectively. Tissue typing showed A2, A3, B15, and Bw47.

\section{CASE 2}

A man aged 59 when first seen in June 1973 gave a 5-year history of rheumatoid arthritis mainly affecting his fingers, elbows, and knees. At this time he was noted to have modest ankle oedema. A chest $x$-ray showed bilateral basal fibrosis, and he admitted to grade 3 dyspnoea and to smoking up to 30 cigarettes daily. $\mathrm{Hb}$ was $11.8 \mathrm{~g} / \mathrm{dl}$ and the ESR was $90 \mathrm{~mm} / 1 \mathrm{st}$ hour. Treatment was started with indomethacin and gold injections. The arthritis improved considerably and the ESR dropped to $15 \mathrm{~mm} / 1$ st hour. However, he developed a skin rash, and gold therapy was stopped. Further deterioration of his arthritis necessitated the use of D-penicillamine, increasing to a dose of $450 \mathrm{mg}$ /day.

In January 1975 his arthritis was controlled except for persistent synovitis of both knees requiring bilateral yttrium-90 synovectomies. Shortly afterwards he developed a light-sensitive rash, his platelet count dropped to $45 \times 10^{9} / 1$, and D-penicillamine was discontinued.

In May 1975 he compalined of night sweats, in- creasing dyspnoea, a productive cough, and easy bruising, and remarked that all his finger and toe $\overrightarrow{\bar{c}}$ nails had turned yellow over the preceding 3 weeks On examination he was unwell, anaemic, and had? signs of right basal collapse and ankle oedema. Chest $x$-ray showed a right basal pleural effusion $\overrightarrow{\widetilde{\sigma}}$ and segmental collapse. Other investigations showed: $\mathrm{Hb} 10.9 \mathrm{~g} / \mathrm{dl}$; ESR $133 \mathrm{~mm} / 1 \mathrm{st}$ hour; leucocytew count $8.2 \times 10^{9} / 1$, with toxic granulation; platelets $\vec{\circ}$ $13 \times 10^{9} / 1$; latex test positive with a DAT of $1: 64 ;$ ANA positive; anti-DNA antibodies negative. Bonew marrow examination suggested a drug-inducedo thrombocytopenia, and the red cell life spano measured by chromium ${ }^{-51}$ was 80 days. Repeated ${ }_{\infty}^{\omega}$ aspirations of the pleural effusion produced purulentior fluid from which a penicillin-sensitive anaerobic streptococcus was grown. Bronchial and pleural ${ }_{0}^{v}$ biopsies showed inflammatory changes.

A diagnosis of infection in a postpneumonic $\vec{P}$ effusion secondary to an apparently generalised marrow suppression possibly related to D-penicil-응 lamine therapy was made. Daily drainage of the effusion and local instillation of penicillin $G$ to- $\vec{e}$ gether with systemic penicillin was started. $\mathrm{He}_{0}^{-}$ developed heart failure which responded to diuretics, a profound anaemia requiring 3 transfusions, and separate basal and apical pneumothoraces requiring 2 underwater seal drains.

Over the course of 2 months his chest and haematological indices improved, his dyspnoea lessened, and his nails returned to a normal colour. $\overrightarrow{\overrightarrow{0}}$ By 1976 he could walk 2 miles $(3 \mathrm{~km})$ and required 3 only indomethacin and analgesics for his arthritis. However, his chest $x$-ray still showed bilateral basal fibrosis.

CASE 3

A man aged 56 was admitted to the Nuffield Orthopaedic Centre in January 1972 with a 10-week history of polyarthritis affecting virtually all hiso joints and associated with general malaise. Ankle oedema, not previously a problem, becameo apparent after the onset of the arthritis. He gave a history of 'nephritis' at the age of 27 and peptico ulceration in 1968 responding to conservativen therapy, and complained of recurrent sinusitis forN about 30 years. He smoked heavily and had $a_{O}^{\omega}$ chronic cough productive of mucoid sputum.

On examination he was unwell, with palpable axillary lymph nodes. He showed signs of emphysema, with numerous scattered rhonchi. There was an active synovitis especially involving the

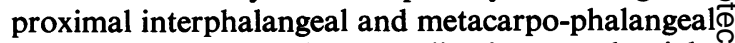
joints of the hands, a large popliteal cyst at the right knee, and a rheumatoid nodule on the left elbow.

Investigations at that time showed $\mathrm{Hb} 11.5 \mathrm{~g} / \mathrm{dl}, \stackrel{2}{\circ}$ 
ESR $68 \mathrm{~mm} / 1$ st hour; white cell count $12.9 \times 10^{9} / 1$; latex test positive with a DAT of $1: 256$; urea $5 \cdot 3$ $\mathrm{mmol} / \mathrm{l}$; albumin $31 \mathrm{~g} / \mathrm{l}$. Radiographs of the feet showed erosions, and a chest $x$-ray lung markings much increased with fibrosis and bullae at both bases.

He improved considerably after treatment with bed rest, splintage, intravenous iron, and a short course of ACTH, and was discharged on ibuprofen. By the time of discharge his haemoglobin had risen to $14.3 \mathrm{~g} / \mathrm{dl}$, the albumin to $43 \mathrm{~g} / \mathrm{l}$, and the ESR had fallen to $35 \mathrm{~mm} / 1$ st hour.

During the next few months he noticed that all his finger and toe nails had turned yellow and that they grew very slowly. He continued to have fairly active arthritis and was seen intermittently in the outpatient department. In 1978 he was found to have severe pitting oedema of both feet and ankles, extending almost to the knees. All his finger and toe nails were yellow and showed increased curvature. He was dyspnoeic on slight exertion, and there were scattered rhonchi in the chest, but no signs of cardiac failure. He had very nasal speech and complained of frequent headaches and a postnasal drip related to his sinusitis. Active synovitis was still present in many joints, and there was swelling of both olecranon bursae.

Investigations showed $\mathrm{Hb} 13.9 \mathrm{~g} / \mathrm{dl}$; ESR 30 $\mathrm{mm} / 1$ st hour; white cell count $9.3 \times 10^{9} / 1$; latex test positive with a DAT of 1:2048; ANA negative; urea $5.6 \mathrm{mmol} / \mathrm{l}$; albumin $40 \mathrm{~g} / \mathrm{l}$; liver function tests normal; serum IgG $13 \cdot 1 \mathrm{~g} / \mathrm{l}$, serum IgA $2 \cdot 4$ $\mathrm{g} / \mathrm{l}$, serum IgM $0.7 \mathrm{~g} / \mathrm{l}$. Chest $x$-ray showed increased fibrosis with basal pleural adhesions and bullae.

\section{Discussion}

Patients with a congenital deficiency of the lymphatics often do not develop persistent lymphoedema until an episode such as infection, insect bite, or injury increases the local capillary permeability, resulting in an increased load for the deficient lymphatics. A similar mechanism may operate in the pleural space when respiratory infection, by damaging the lymphatic drainage, results in persistent effusions (Emerson, 1966).

Jayson and Barks (1971) found a generalised increase in the coefficient of capililary filtration in rheumatoid arthritis, and Jayson et al. (1971) showed a significant slowing of lymphatic clearance in rheumatoid patients. It therefore seems probable that active rheumatoid disease may be a factor in overloading a deficient lymphatic drainage system, thus producing lymphoedema and possibly yellow nails.
The first 2 patients described had established seropositive rheumatoid arthritis of several years' duration before developing the yellow nail syndrome; both had chest infections with pleural effusions, both had taken D-penicillamine, and both had evidence of immunodeficiency. In the first case immunodeficiency was suggested by a persistently low serum IgA level. This may have been precipitated by D-penicillamine (Hjalmarson et al., 1977; Stephens and Fenton, 1977; Johns et al., 1978), or be a demonstration of autoimmune disease associated with primary IgA deficiency (Ammann and Hong, 1971). However, no prepenicillamine IgA level was available. A further possibility is that the $\operatorname{IgA}$ deficiency was related to the yellow nail syndrome. Nakielna et al. (1976) described a patient with this syndrome in whom immunoelectrophoresis showed complete absence of IgA on several occasions. It is interesting that recurrent infections, particularly of the sinuses and respiratory tract, are a prominent feature of both IgA deficiency (Ammann and Hong, 1971) and the yellow nail syndrome (Hiller et al., 1972; Nakielna et al., 1976).

The second patient experienced a profound marrow depression possibly related to D-penicillamine therapy, and persistent respiratory infection resulted; however, the serum IgA level was never measured. The third patient first developed yellow nails and peripheral oedema shortly after the onset of his arthritis, although he had a long history of sinusitis, and his initial chest $x$-ray suggested longstanding pulmonary disease. However, his IgA level was normal.

The yellow nail syndrome was found in association with immunological deficiency states by Siegelman et al. (1969). They described 2 siblings with congenital lymphoedema and recurrent pleural effusions in adult life, 1 of whom had yellow toe nails. Abnormalities of the immune response were suggested by recurrent chest and skin infections, hypogammaglobulinaemia, and episodic lymphopenia, and 1 patient developed Hodgkin's disease as a terminal event. In the 12 cases reported by Hiller et al. (1972) protein electrophoresis was performed in 11 and only 1 showed borderline hypogammaglobulinaemia, but differential immunoelectrophoresis was not reported. Leucopenia or lymphopenia were not found. They suggested that the yellow nail syndrome may include a predisposition to the development of lymphomatous or sarcomatous neoplasms, and D'Souza (1970) has reported benign monoclonal macroglobulinaemia in a patient with this syndrome.

The yellow nail syndrome is rare and its occurrence in association with rheumatoid arthritis in these 3 cases may be more than a chance finding. The significance of this association is uncertain, but 
it may be related to primary or secondary disorders of immune status. It is interesting to note that the yellow nails disappeared in our second case as the marrow suppression spontaneously resolved.

The authors wish to thank Dr A. G. Mowat and Dr J. M. Gumpel for permission to report their patients.

\section{References}

Ammann, A. J., and Hong, R. (1971). Selective IgA deficiency: presentation of 30 cases and a review of the literature. Medicine, 50, 223-236.

Boddington, M. M., Spriggs, A. I., Morton, J. A., and Mowat, A. G. (1971). Cytodiagnosis of rheumatoid pleural effusions. Journal of Clinical Pathology, 24, 95-106.

D'Souza, M. F. (1970). Generalized lymphoedema with yellow nails, pleural effusions and macroglobulinaemia. Proceedings of the Royal Society of Medicine, 63, 456.

Emerson, P. A. (1966). Yellow nails, lymphoedema, and pleural effusions. Thorax, 21, 247-253.

Hiller, E., Rosenow, E. C., and Olsen, A. M. (1972). Pulmonary manifestations of the yellow nails syndrome. Chest, 61, 452-458.

Hjalmarson, O., Hanson, L. A., and Nilsson, L-A. (1977).
IgA deficiency during D-penicillamine treatment. British Medical Journal, 1, 549.

Jayson, M. I. V., and Barks, J. S. (1971). Oedema in rheumatoid arthritis: changes in the coefficient of capillary $\square$ filtration. British Medical Journal, 2, 555-557.

Jayson, M. I. V., Cavill, I., and Barks, J. S. (1971). Lymphatic clearance rates in rheumatoid arthritis. Annals of the Rheumatic Diseases, 30, 638-639.

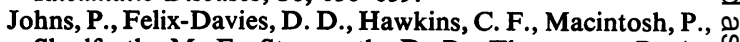
Shadforth, M. F., Stanworth, D. R., Thompson, R. A., o and Williamson, N. (1978). IgA deficiency in patients with $\vec{O}$ rheumatoid arthritis treated with D-penicillamine or gold. Annals of the Rheumatic Diseases, 37, 289.

Nakielna, E. M., Wilson, J., and Ballon, H. S. (1976). Yellow-nail syndrome: report of three cases. Canadian Medical Association Journal, 115, 46-48.

Samman, P. D., and White, W. F. (1964). The 'yellow-nail' syndrome. British Journal of Dermatology, 76, 153-157.

Sharvill, D. E. (1966). In discussion: Yellow nail syndrome if with bilateral bronchiectasis. Proceedings of the Royal $\mathrm{v}$ Society of Medicine, 59, 448.

Siegelman, S. S., Heckman, B. H., and Hasson, J. (1969). 을 Lymphoedema, pleural effusions and yellow nails. Diseases of the Chest, 56, 114-117.

Stephens, A. D., and Fenton, J. C. B. (1977). Serum immunoglobulins in D-penicillamine-treated cystinurics. Proceedings of the Royal Society of Medicine, 70, Supplement 3, 31-33. 